\title{
Regional and national guideline recommendations for digital ano-rectal examination as a means for anal cancer screening in HIV positive men who have sex with men: a systematic review
}

Jason J Ong ${ }^{1 *}$, Marcus Chen ${ }^{2,3}$, Andrew E Grulich ${ }^{4}$ and Christopher K Fairley ${ }^{1,2,3}$

\begin{abstract}
Background: Although anal cancer is common in HIV positive men who have sex with men, few centres offer systematic screening. Regular digital ano-rectal examination (DARE) is a type of screening that has been recommended by some experts. How widely this forms part of HIV management guidelines is unclear.

Methods: The protocol was registered prospectively (CRD42013005188; www.crd.york.ac.uk/PROSPERO/). We systematically reviewed 121 regional and national HIV guidelines and searched for guidelines from http://hivinsite. ucsf.edu/global?page $=$ cr-00-04\#SauguidelineX, PubMed and Web of Science databases up to $5^{\text {th }}$ August 2013 for recommendations of DARE as a means of anal cancer screening in HIV positive MSM. Guidelines were examined in detail if they were clinical guidelines, including both prevention and treatment protocols and were in English. Guidelines were excluded if they were restricted to limited areas (e.g. antiretroviral therapy only, children or pregnant women, strategies for prevention/testing). Information was extracted regarding recommendation of DARE as a screening method, the frequency of DARE recommended, target population for screening and the strength of evidence supporting this.
\end{abstract}

Results: 30 regional and national guidelines were included and examined in detail. Only 2 recommended DARE. The 'European AIDS Clinical Society Guidelines' recommends DARE every 1-3 years for HIV positive MSM whilst the 'US Guideline for prevention and treatment of opportunistic infections in HIV-infected adults and adolescents' recommends an annual DARE for the HIV + population in general. None of these guidelines specify the age of commencing screening. In each case, the highest level of evidence supporting these two recommendations was expert opinion.

Conclusions: Few HIV guidelines discuss or recommend DARE as a means of anal cancer screening. Studies of the efficacy, acceptability and cost-effectiveness of DARE are needed to assess its role in anal cancer screening.

Keywords: Anal cancer screening, Systematic review, Guidelines, Digital ano-rectal examination, HIV positive, Men who have sex with men

\footnotetext{
* Correspondence: j.ong@unimelb.edu.au

${ }^{1}$ Melbourne School of Population and Global Health, University of

Melbourne, 580 Swanston Street, Carlton, Victoria 3053, Australia

Full list of author information is available at the end of the article
} 


\section{Background}

Anal cancer is defined as cancers arising from the squamous and glandular epithelia of the anus. The great majority are squamous cell carcinomas (SCC) [1-4]. Anal cancer has received little attention given its rarity in the general population $(\sim 1-2$ in 100,000$)$ [1-3,5]. However, incidence is higher among men who have sex with men (MSM) especially those who are HIV-positive. A recent meta-analysis estimated the anal cancer incidence rate to be 46 per 100,000 in HIV positive MSM [6]. However there have been reports as high as 131 to 137 per 100,000 in large US cohorts of HIV-positive MSM, and a number have reported an increasing incidence in the post-highly active antiretroviral therapy (HAART) era $[7,8]$. Anal cancer is now the most common non-AIDS defining cancer in HIV infected people in Australia [9].

The morbidity associated with anal cancer and its treatments is significant. Although local excision may be considered for small well differentiated anal cancers, in most instances chemo-radiotherapy is needed for treatment $[10,11]$ with its potential long term side effects such as impotence. The quality of life for someone with anal cancer has been estimated to be worse than those with either oropharyngeal, vaginal, vulvar or penile cancer [12].

Despite the high incidence, and morbidity of anal cancer in some populations, there is still no consensus recommendation for how to effectively screen for anal cancer for those at highest risk (i.e. HIV positive MSM). There are two approaches suggested 1) detecting early cancers using regular DARE or 2) detecting precursor lesions using an anal cytology-based program with diagnostic high resolution anoscopy (HRA) to identify highgrade squamous intraepithelial lesion (HSIL) [13], which can then be treated using a variety of ablative or other treatments (typically, DARE is also performed in this approach). Other potential approaches may include HRA alone [14] or DARE with subsequent cytology/HRA [15]. Some centres have adopted the stance that given the relatively high burden of anal cancer in the HIV population, anal-cytology based screening and treatment for HGAIN should be implemented. They argue that the similarities to the cervical cancer model justifies screening until this evidence is available $[16,17]$. However there remains significant barriers to implement an anal cytological screening service including low sensitivity to detect HSIL due to a large percentage of HIV-positive MSM with abnormal cytology [6], lack of highresolution anoscopists and no evidence from randomized controlled trials that treatment of HSIL prevents development of anal cancer [17]. At this point in time the majority of HIV clinicians do not offer an anal cytology screening service outside a limited number of centres $[18,19]$.
So whilst evidence of screening and treating HSIL continues to gather and clinical expertise develops, should we implement the model of a regular DARE to detect early cancer? Survival from anal cancer is markedly higher if it is treated at an early stage. For instance, the US National Cancer Institute data on 6,411 patients showed that tumours less than $2 \mathrm{~cm}$ at diagnosis had $80 \% 5$ year-survival compared with $45-65 \%$ when the tumour was more than $2 \mathrm{~cm}$ and $20 \%$ for tumours that had metastasized [20]. A case series of 38 HIV-positive men with tumours less than $3 \mathrm{~cm}$ had a 5 year cancer specific survival of $85 \%$ compared to zero in those with tumours greater than $3 \mathrm{~cm}$ [21]. A French series of 69 patients with anal cancers less than $1 \mathrm{~cm}$ reported a $100 \% 5$ year survival [17].

Currently, most anal cancers are detected when they are locally advanced with mean tumor size of 3 to $4 \mathrm{~cm}$ $[11,22,23]$. Thus, earlier diagnosis than currently occurs, for example through the routine use of DARE, has great potential to lead to reduced morbidity. Experts have suggested that all individuals at higher risk for anal cancer should have a regular DARE [24].

Although some published articles suggest regular DARE as a means of screening [25-27], currently only a minority of patients at highest risk for anal cancer receive a regular DARE as a part of their HIV care [28]. Our aim was to determine if this low rate of DARE was because few national guidelines recommended it, or because of a poor uptake of existing guidelines. We systematically reviewed national HIV guidelines to evaluate recommendations for the implementation of regular DARE as part of routine HIV care.

\section{Methods}

\section{Search strategy}

The protocol was prospectively registered in the 'International prospective register of systematic reviews' (www.crd.york.ac.uk/PROSPERO; CRD42013005188). We initially searched for major HIV guidelines through the comprehensive list found on http://hivinsite.ucsf. edu/global?page $=$ cr-00-04\#SauguidelineX $\left(\right.$ accessed $5^{\text {th }}$ August 2013). This website compiles the latest HIV national guidelines from around the world. We searched these 121 HIV guidelines for recommendations regarding the use of DARE for early anal cancer detection. Secondly, we searched the US National Library of Medicine's PubMed (http://ncbi.nlm.nih.gov/pubmed) and Thomson Reuter's ISI Web of Science (http:// thomsonreuters.com/thomson-reuters-web-of-science/) databases using the following text string '(anal OR anus OR ano*) AND (cancer OR carcinoma OR neoplasm OR malignancy OR 'squamous cell carcinoma' OR 'squamous cell cancer') AND (screen*) to search in the field 'title'. 


\section{Inclusion and exclusion criteria}

Guidelines were examined in detail if they were clinical guidelines, including both prevention and treatment protocols. This led to excluding 91 guidelines because they were either guidelines aimed at children or pregnant women $(\mathrm{n}=30)$, specific antiretroviral protocols (15), strategies for HIV prevention/testing (12), or was not published in English (28). 6 other guidelines were excluded because they were discussing HIV infected health care workers (1), nutrition guidelines (1), duplicates (2), home-based care program (1) and work place program (1).

In searching PubMed and Web of Science, the titles and abstracts were examined and 346 full text publications were fully appraised as they met the following criteria: English language, anal cancer or its screening in the HIV positive population. 6 published articles were identified as 'guidelines' and one additional guideline was identified through searching the reference lists of reviewed publications. Of the 7 publications, 4 guidelines were excluded as they were not national guidelines [10,29-31] and another 2 were identified as national guidelines but excluded as they did not mention DARE [32,33]. As a subanalysis, we searched for original articles that utilized DARE alone as a means for anal cancer screening.

\section{Quality assessment and data extraction}

Each of the 30 national HIV guidelines was reviewed for statements regarding anal examination and/or DARE including who to screen and how frequently to screen. The level of evidence quoted to support such a recommendation was also captured. The level of evidence was assessed using the US Preventive Services Task Force for ranking evidence for the effectiveness of screening [34].

Level I denotes evidence from at least one properly designed randomized controlled trial. Level II denotes evidence from well designed controlled trials without randomization, cohort or case-control analytic studies or multiple time series with or without the intervention. Level III denotes evidence from opinions of respected authorities, based on clinical experience, descriptive studies or reports of expert committees.

\section{Results}

Figure 1 is a flow diagram for the literature search and guideline selection. Tables 1 and Figure 2 summarizes the

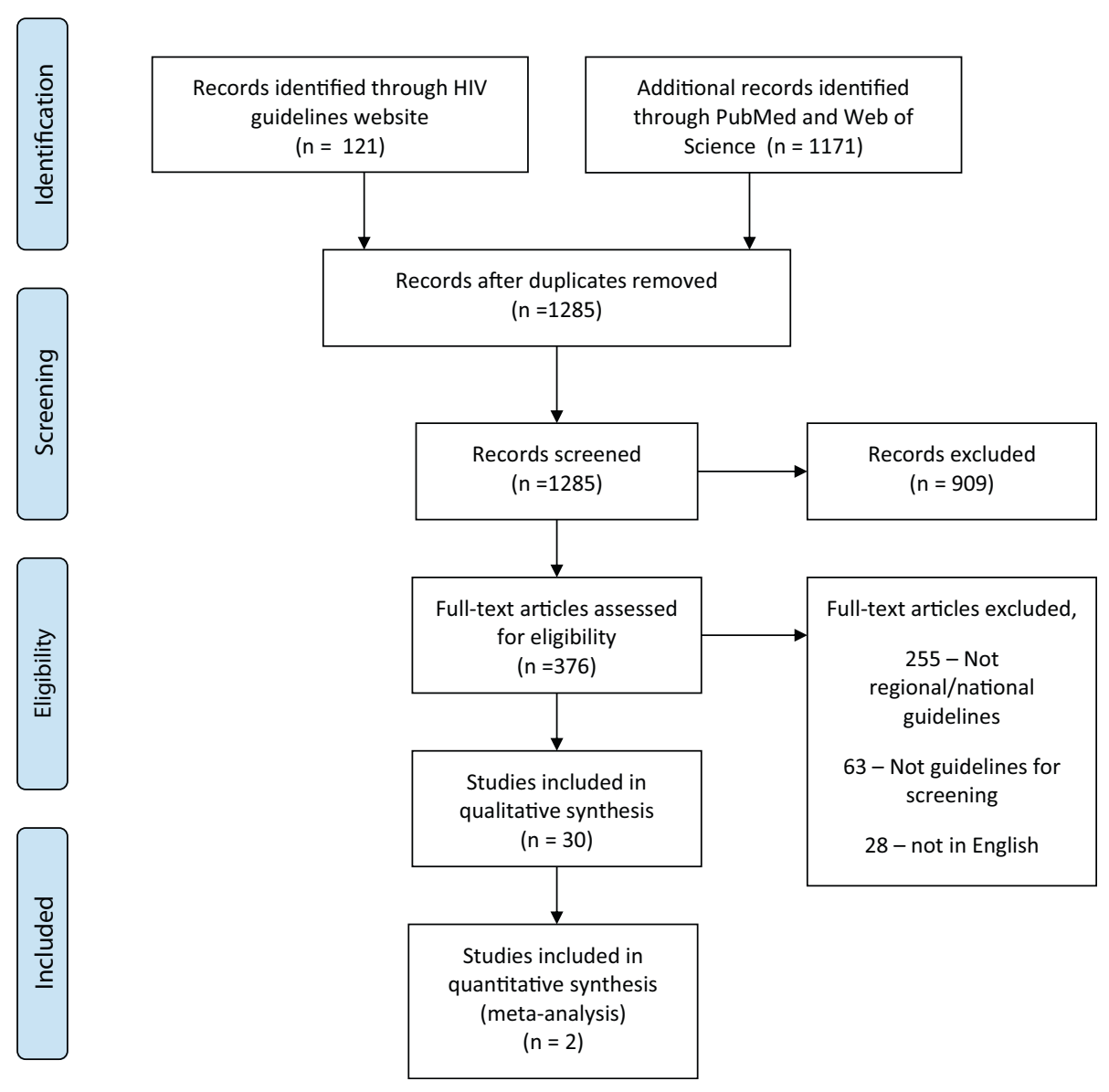

Figure 1 Search Strategy. 
countries covered by the national guidelines reviewed. Full text was not accessible for the countries in bold because the guidelines were not in English.

Two guidelines specifically discuss DARE (Table 2). The European AIDS Clinical Society Guidelines specifically recommend that 'homosexual men' should have a 'digital rectal exam \pm Papanicolau test' with a screening interval of ' $1-3$ years'. The evidence of benefit was quoted as 'unknown advocated by some experts' [35]. Although this is the most specific recommendation of all the guidelines reviewed, there was no explicit description of how this recommendation was derived nor was it referenced. These guidelines did not explicitly describe the process that was undertaken to arrive at a recommendation and there was no "level of

Table 1 Number of HIV guidelines reviewed

\begin{tabular}{ll}
\hline Reviewed (number of guidelines) & $\begin{array}{l}\text { Not reviewed because was } \\
\text { not available in English }\end{array}$ \\
\hline Regional & \\
World (15) & Latin America (2) \\
East Asia and Pacific (1) & \\
Eastern Europe and Central Asia (2) & \\
Carribean (1) & \\
South and South East Asia (3) & \\
Western Europe (3) & \\
National & \\
Australia (1) & Argentina (2) \\
Botswana (1) & Brazil (6) \\
Canada (5) & Bhutan (1) \\
China (2) & Chile (1) \\
Egypt (3) & Colombia (1) \\
Ethiopia (5) & France (1) \\
Guyana (1) & Germany (2) \\
Hong Kong (2) & \\
India (5) & Mexico (2) \\
Kenya (4) & Mozambique (1) \\
Malawi (1) & Spain (5) \\
Malaysia (2) & Ukraine (3) \\
Namibia (2) & Uruguay (1) \\
Nepal (1) & \\
Pakistan (2) & \\
Russian federation (2) & \\
South Africa (4) & \\
Swaziland (1) & \\
Tanzania (2) & \\
\hline & \\
\hline United Kingdom (8) & \\
\hline
\end{tabular}

evidence' grading of this specific recommendation for anal cancer screening.

The second guideline that refers to DARE was the USA's 'Guideline for prevention and treatment of opportunistic infections in HIV-infected adults and adolescents'. This guideline did not recommend DARE but made the statement that it may be useful: 'An annual digital anal examination may be useful to detect masses on palpation that could be anal cancer'. The guideline did not recommend a frequency for DARE or identify a specified population that should be screened and specifically did not limit their suggestion to HIV positive MSM. The recommended level of evidence for this is BIII, which refers to 'moderate recommendation for the statement' and 'expert' opinion. The process of derivation of this recommendation was described as through those with expertise in this area reviewing the literature to produce draft guidelines. The recommendations were then reviewed by the Opportunistic Infections Working Group of National Institutes of Health. Final versions were reviewed and endorsed by $C D C$, the National Institutes of Health and the HIV Medicine association of the Infectious Diseases Society of America.

We did identify two other guidelines that referred to the issue of anal cancer but did not make specific recommendations about DARE. The British HIV association guidelines for HIV-associated malignancies do not recommend DARE and implies that patients do their own anal examination [33]. The guideline stated that the role of annual anal cytology and anoscopy is not yet proven; however, patients should be encouraged to check and report any lumps noticed in the anal canal'. This again was based only on expert opinion (Level III) with no references to any published studies. It is important to note that these guidelines are currently being revised but in light of the lack of published evidence for DARE, we do not believe that the recommendation is likely to alter at this stage. The World Health Organization's Treatment and care protocols for the European Region [36] acknowledge that 'anal cancer is strongly associated with HPV infection and it is significantly more likely among MSM who are HIV infected' and that 'any patient suspected of cancer should be examined by an oncologist and referred to the oncology clinic as needed'. However no guidance is provided as to what examination is needed. This again is based only on expert opinion (Level III) with no references to any published studies.

In our subanalysis of original articles utilizing DARE as a screening tool, we found one article that described the acceptability of DARE to a HIV-positive MSM population [37]. However this study did not provide any efficacy data for DARE. 


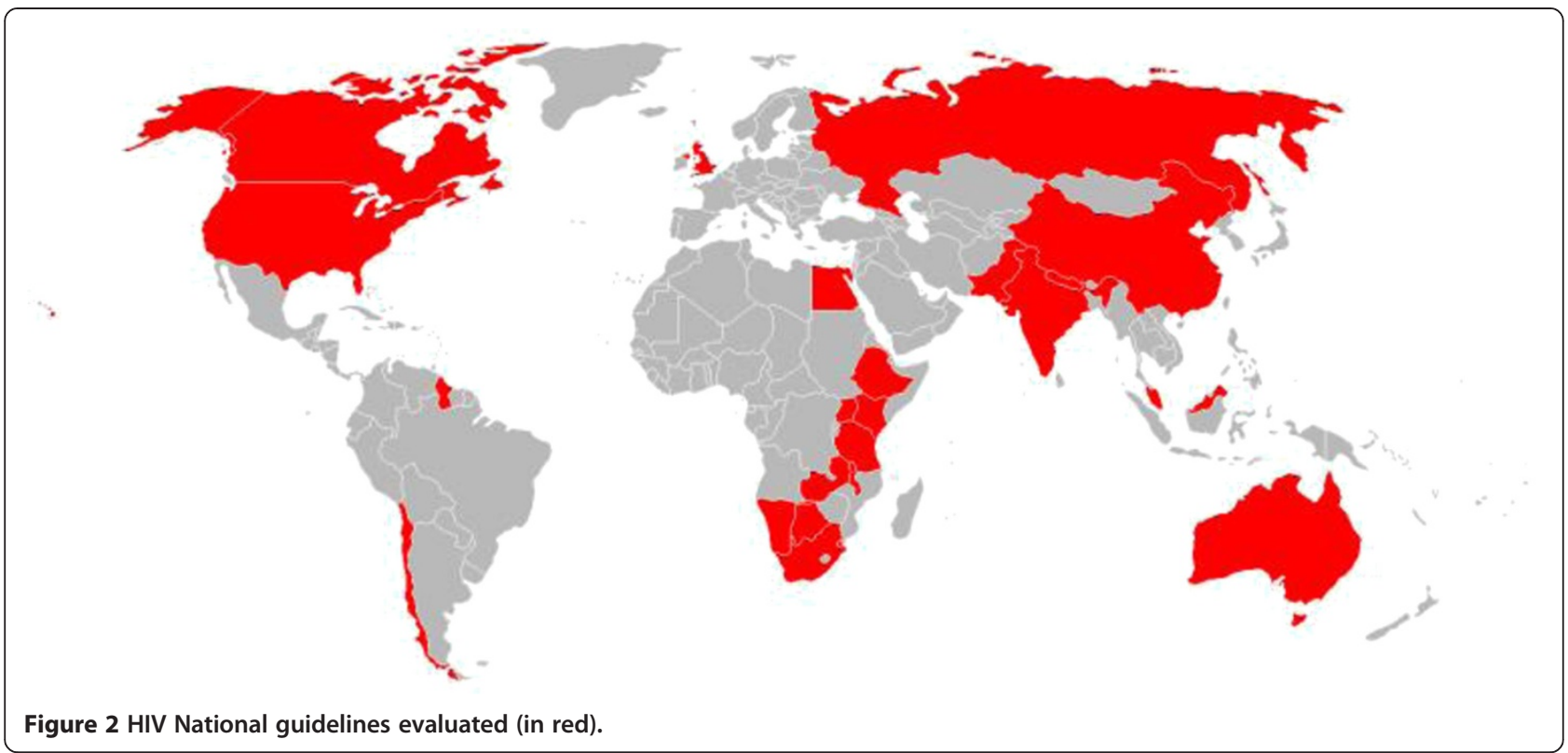

\section{Discussion}

Although DARE is recommended by experts [25-27], this has not been reflected in HIV guidelines. In our review of regional and national HIV guidelines, we found only one that recommended regular DARE and another that considered it may be useful. The highest level of evidence for this was expert opinion. This highlights the need for more data on whether DARE is effective for the early detection of anal cancer in HIV positive MSM. A recent study of 138 HIVpositive MSM with anal cancer found that early anal cancer detection was possible in asymptomatic men if they were closely followed up with regular DARE [38]. However, to date, there have not been any studies evaluating whether widespread implementation of regular DARE in those at highest risk for anal cancer (i.e. HIV-positive MSM) would reduce the morbidity and mortality from anal cancer and its management. Currently DARE is not commonly undertaken. One study found that within a HIV clinic, only $10 \%$ of their patients were receiving anal cancer screening either by DARE and/or cytology [28]. Yet anal cancer in HIV positive MSM is the most common non AIDS defining cancer in this group, and as frequent as the common cancers in the general community such as bowel cancer, for which screening programs are in place.
To our knowledge, this is the first examination of regional and national HIV guidelines to quantify the degree of support for DARE to detect early anal cancers. Our systematic review specifically did not review the literature on recommendations for DARE in the general community because the incidence of this cancer is about 100 fold higher in HIV positive MSM. This means that recommendations made in the general community may be quite different because the positive predictive value, negative predictive value and costs will also be very different. We did not evaluate guidelines that were in languages other than English. This excluded 28 of the 121 guidelines and so it is possible that important recommendations based on higher levels of evidence were missed.

The limited range of guidelines in relation to DARE reflects the absence of studies addressing the key screening issues in relation to prevention of morbidity from anal cancer [39]. Some of these criteria are clearly satisfied in relation to DARE screening for anal cancer. These are that anal cancer is an important health problem in people with HIV, it has a recognizable early stage and effective treatment leading to better outcomes for early stage diagnosis. Other criteria for an effective anal

Table 2 Guidelines that mention DARE as a means for anal cancer screening

\begin{tabular}{|c|c|c|c|c|}
\hline Guidelines & Recommendation & $\begin{array}{l}\text { Target } \\
\text { population }\end{array}$ & $\begin{array}{l}\text { Frequency } \\
\text { of DARE }\end{array}$ & $\begin{array}{l}\text { Level of } \\
\text { evidence }\end{array}$ \\
\hline $\begin{array}{l}\text { European AIDS Clinical Society } \\
\text { Guidelines [33] }\end{array}$ & 'digital rectal exam +/- Papanicolau test' & $\begin{array}{l}\text { HIV positive } \\
\text { MSM }\end{array}$ & $\begin{array}{l}\text { Every } 1-3 \\
\text { years }\end{array}$ & $\begin{array}{l}\text { III (expert } \\
\text { opinion) }\end{array}$ \\
\hline $\begin{array}{l}\text { US Guideline for prevention and treatment of } \\
\text { opportunistic infections in HIV-infected adults } \\
\text { and adolescents [38] }\end{array}$ & $\begin{array}{l}\text { 'digital rectal examination as an important procedure to detect } \\
\text { masses on palpation that might be anal cancer' }\end{array}$ & $\begin{array}{l}\text { Not } \\
\text { specified }\end{array}$ & Annually & $\|$ \\
\hline
\end{tabular}


cancer screening test are not yet met. DARE has not yet been proven to be a simple and acceptable test, the distribution of test values in the target population is not clear, there is no general agreement on who should be screened and how, and the cost of the procedure is not well documented. However, recent data has provided data suggesting a high level of acceptability of the procedure and suggested minimal additional health-care cost [37]. Questions remain in relation to the impact of having a regular DARE on quality of life measures and costs associated with false negative and false positive results. Future screening studies must also include an evaluation of the potential for increased anxiety and worry [40]. Furthermore, there remains no evidence of DARE's efficacy or efficiency (i.e. sensitivity, specificity, positive predictive value, negative predictive value), the acceptability of DARE for doctors, nor any cost-effectiveness evaluation of DARE. If DARE is to be recommended into routine HIV care, this information is urgently needed.

\section{Conclusion}

Anal cancer is an urgent health priority for HIV-positive MSM. Although some experts have recommended regular DARE as a means of detection of anal cancer, few HIV guidelines discuss or recommend DARE as a means of anal cancer screening. There is a need for further studies of the efficacy, acceptability and cost-effectiveness of DARE before its role in anal cancer screening can be determined.

\section{Abbreviations}

DARE: Digital ano-rectal examination; HIV: Human immunodeficiency virus; HSIL: High-grade squamous intra-epithelial lesion; MSM: Men who have sex with men; SCC: Squamous cell carincoma.

\section{Competing interests}

The authors declare that they have no competing interests.

\section{Authors' contributions}

JO and CF designed the review. JO coordinated the review. JO, MC, AG and CF did the analysis of the data, wrote the review and revised the manuscript. All authors read and approved the final manuscript.

\section{Acknowledgement}

The study was funded by a National Health and Medical Research Council Postgraduate Scholarship.

\section{Author details}

${ }^{1}$ Melbourne School of Population and Global Health, University of Melbourne, 580 Swanston Street, Carlton, Victoria 3053, Australia. ${ }^{2}$ Melbourne Sexual Health Centre, 580 Swanston Street, Carlton, Victoria 3053, Australia. ${ }^{3}$ Central Clinical School, Monash University, Clayton Victoria 3168, Australia. ${ }^{4}$ Kirby Institute, University of New South Wales, Sydney NSW 2052, Australia.

Received: 9 September 2013 Accepted: 4 July 2014

Published: 1 August 2014

\section{References}

1. Jin F, Stein AN, Conway EL, Regan DG, Law M, Brotherton JM, Hocking J, Grulich AE: Trends in anal cancer in Australia, 1982-2005. Vaccine 2011, 29(12):2322-2327.
2. Johnson LG, Madeleine MM, Newcomer LM, Schwartz SM, Daling JR: Anal cancer incidence and survival: the surveillance, epidemiology, and end results experience, 1973-2000. Cancer 2004, 101(2):281-288.

3. Joseph DA, Miller JW, Wu X, Chen WW, Morris CR, Goodman MT, Villalon-Gomez JM, Williams MA, Cress RD: Understanding the burden of human papillomavirus-associated anal cancers in the US. Cancer 2008, 113(10 Suppl):2892-2900.

4. Brewster $\mathrm{DH}$, Bhatti $\mathrm{LA}$ : Increasing incidence of squamous cell carcinoma of the anus in Scotland, 1975-2002. Br J Cancer 2006, 95(1):87-90.

5. Patel $P$, Hanson DL, Sullivan PS, Novak RM, Moorman AC, Tong TC, Holmberg SD, Brooks JT: Incidence of types of cancer among HIV-infected persons compared with the general population in the United States, 1992-2003. Ann Intern Med 2008, 148(10):728-736.

6. Machalek DA, Poynten M, Jin F, Fairley CK, Farnsworth A, Garland SM, Hillman RJ, Petoumenos K, Roberts J, Tabrizi SN, Templeton DJ, Grulich AE: Anal human papillomavirus infection and associated neoplastic lesions in men who have sex with men: a systematic review and meta-analysis. Lancet Oncol 2012, 13(5):487-500.

7. Silverberg MJ, Lau B, Justice AC, Engels E, Gill MJ, Goedert JJ, Kirk GD, D'Souza G, Bosch RJ, Brooks JT, Napravnik S, Hessol NA, Jacobson LP, Kitahata MM, Klein MB, Moore RD, Rodriguez B, Rourke SB, Saag MS, Sterling TR, Gebo KA, Press N, Martin JN, Dubrow R: Risk of anal cancer in HIV-infected and HIV-uninfected individuals in North America. Clin Infect Dis 2012, 54(7):1026-1034.

8. D'Souza G, Wiley DJ, Li X, Chmiel JS, Margolick JB, Cranston RD, Jacobson LP: Incidence and epidemiology of anal cancer in the multicenter AIDS cohort study. J Acquir Immune Defic Syndr 2008, 48(4):491-499.

9. van Leeuwen MT, Vajdic CM, Middleton MG, McDonald AM, Law M, Kaldor JM, Grulich AE: Continuing declines in some but not all HIV-associated cancers in Australia after widespread use of antiretroviral therapy. AIDS 2009, 23(16):2183-2190.

10. Glynne-Jones R, Northover JM, Cervantes A: Anal cancer: ESMO Clinical Practice Guidelines for diagnosis, treatment and follow-up. Ann Oncol 2010, 21(Suppl 5):v87-v92.

11. Tomaszewski JM, Link E, Leong T, Heriot A, Vazquez M, Chander S, Chu J, Foo M, Lee MT, Lynch CA, Mackay J, Michael M, Tran P, Ngan SY: Twenty-five-year experience with radical chemoradiation for anal cancer. Int J Radiat Oncol Biol Phys 2012, 83(2):552-558.

12. Conway EL, Farmer KC, Lynch WJ, Rees GL, Wain G, Adams J: Quality of life valuations of HPV-associated cancer health states by the general population. Sex Transm Infect 2012, 88(7):517-521.

13. Darragh TM, Colgan TJ, Thomas Cox J, Heller DS, Henry MR, Luff RD, McCalmont T, Nayar R, Palefsky JM, Stoler MH, Wilkinson EJ, Zaino RJ, Wilbur DC: The Lower Anogenital Squamous Terminology Standardization project for HPV-associated lesions: background and consensus recommendations from the College of American Pathologists and the American Society for Colposcopy and Cervical Pathology. Int J Gynecol Pathol 2013, 32(1):76-115.

14. Lam JM, Hoch JS, Tinmouth J, Sano M, Raboud J, Salit IE: Cost-effectiveness of screening for anal precancers in HIV-positive men. AIDS 2011, 25(5):635-642

15. Machalek DA, Grulich AE, Hillman RJ, Jin F, Templeton DJ, Tabrizi SN, Garland SM, Prestage G, McCaffery K, Howard K, Tong W, Fairley CK, Roberts J, Farnsworth A, Poynten IM: The Study of the Prevention of Anal Cancer (SPANC): design and methods of a three-year prospective cohort study. BMC Public Health 2013, 13:946.

16. Cachay ER, Mathews WC: Human papillomavirus, anal cancer, and screening considerations among HIV-infected individuals. AIDS Rev 2013, 15(2):122-133.

17. Smyczek $P$, Singh A, Romanowski B: Anal intraepithelial neoplasia: review and recommendations for screening and management. Int J STD AIDS 2013, 24(11):843-851.

18. Anderson JS, Vajdic C, Grulich AE: Is screening for anal cancer warranted in homosexual men? Sex Health 2004, 1(3):137-140.

19. Grulich AE, Hillman R, Brotherton JM, Fairley CK: Time for a strategic research response to anal cancer. Sex Health 2012, 9(6):628-631.

20. Madeleine MM: Cancer of the anus. In SEER Survival Monograph: Cancer survival among adults SEER Program, 1988-2001, Patient and Tumor Characateristics. Edited by Ries L. Bethesda: National Cancer Institute, SEER Program; 2007. vol. NIH Pub. 07-6215.

21. Wexler A, Berson AM, Goldstone SE, Waltzman R, Penzer J, Maisonet OG, McDermott B, Rescigno J: Invasive anal squamous-cell carcinoma in the 
HIV-positive patient: outcome in the era of highly active antiretroviral therapy. Dis Colon Rectum 2008, 51(1):73-81.

22. Deans GT, McAleer JJ, Spence RA: Malignant anal tumours. Br J Surg 1994, 81(4):500-508

23. Read T, Huson K, Millar J, Haydon A, Porter I, Grulich A, Hocking J, Chen M, Bradshaw C, Fairley C: Size of anal squamous cell carcinomas at diagnosis: a retrospective case series. Int J STD AIDS 2013, 24(11):879-882.

24. Palefsky J: Human papillomavirus and anal neoplasia. Curr HIV/AIDS Rep 2008, 5(2):78-85

25. Moran MG, Barkley TW Jr, Hughes CB: Screening and management of anal dysplasia and anal cancer in HIV-infected patients: a guide for practice. J Assoc Nurses AIDS Care 2010, 21(5):408-416.

26. Steele SR, Varma MG, Melton GB, Ross HM, Rafferty JF, Buie WD, Standards Practice Task Force of the American Society of Colon and Rectal Surgeons: Practice parameters for anal squamous neoplasms. Dis Colon Rectum 2012, 55(7):735-749.

27. Szmulowicz UM, WU JS: Squamous cell carcinoma of the anal canal: a review of the aetiology, presentation, staging, prognosis and methods available for treatment. Sex Health 2012, 9(6):593-609.

28. Kwong JJ, Cook P, Bradley-Springer L: Improving anal cancer screening in an ambulatory HIV clinic: experience from a quality improvement initiative. AIDS Patient Care STDS 2011, 25(2):73-78.

29. Palefsky JM, Holly EA, Hogeboom CJ, Berry JM, Jay N, Darragh TM: Anal cytology as a screening tool for anal squamous intraepithelial lesions. J Acquir Immune Defic Syndr Hum Retrovirol 1997, 14(5):415-422.

30. Arnold D, Girling A, Stevens A, Lilford R: Comparison of direct and indirect methods of estimating health state utilities for resource allocation: review and empirical analysis. BMJ 2009, 339:b2688.

31. Mani D, Aboulafia DM: Screening guidelines for non-AIDS defining cancers in HIV-infected individuals. Curr Opin Oncol 2013, 25(5):518-525.

32. Aberg JA, Kaplan JE, Libman H, Emmanuel P, Anderson JR, Stone VE, Oleske $J M$, Currier JS, Gallant JE: Primary care guidelines for the management of persons infected with human immunodeficiency virus: 2009 update by the HIV medicine Association of the Infectious Diseases Society of America. Clin Infect Dis 2009, 49(5):651-681.

33. Bower M, Collins S, Cottrill C, Cmynarski K, Montoto S, Nelson M, Nwokolo N, Powles T, Stebbing J, Wales N, Webb A: British HIV Association guidelines for HIV-associated malignancies 2008. HIV Med 2008, 9(6):336-388.

34. Lawrence R: Guide to Clinical Preventive Services: Report of the US Preventive Services Task Force. Washington DC: DIANE Publishing; 1989.

35. European AIDS Clinical Society Guidelines-version 6.1. [http://www.sm.ee/ sites/default/files/content-editors/eesmargid_ja_tegevused/Tervis/Ravimid/ eacsguidelines_v6.1_nov2012.pdf]. Date accessed 6th June 2013.

36. HIV/AIDS Treatment and Care: Clinical protocols for the WHO European Region. [www.euro.who.int/_data/assets/pdf_file/0004/78106/E90840.pdf]. Date accessed 6th June 2013.

37. Read T, Vodstrcil L, Grulich A, Farmer C, Bradshaw C, Chen M, Tabrizi S, Hocking J, Anderson J, Fairley C: Acceptability of digital anal cancer screening examinations in HIV-positive homosexual men. HIV Med 2013, 14(8):491-496

38. Berry JM, Jay N, Cranston RD, Darragh TM, Holly EA, Welton ML, Palefsky JM: Progression of anal high-grade squamous intraepithelial lesions to invasive anal cancer among HIV-infected men who have sex with men. Int J Cancer 2014, 134(5):1147-1155.

39. Wilson JM, Jungner YG: [Principles and practice of mass screening for disease]. Bol Oficina Sanit Panam 1968, 65(4):281-393.

40. Landstra JM, Ciarrochi J, Deane FP, Botes LP, Hillman RJ: The psychological impact of anal cancer screening on HIV-infected men. Psychooncology 2013, 22(3):614-620.

doi:10.1186/1471-2407-14-557

Cite this article as: Ong et al:: Regional and national guideline recommendations for digital ano-rectal examination as a means for anal cancer screening in HIV positive men who have sex with men: a systematic review. BMC Cancer 2014 14:557.

\section{Submit your next manuscript to BioMed Central and take full advantage of:}

- Convenient online submission

- Thorough peer review

- No space constraints or color figure charges

- Immediate publication on acceptance

- Inclusion in PubMed, CAS, Scopus and Google Scholar

- Research which is freely available for redistribution

Submit your manuscript at www.biomedcentral.com/submit
Ciomed Central 